\title{
Thalamocortical Mechanisms for the Anteriorization of Alpha Rhythms during Propofol-Induced Unconsciousness
}

\author{
Sujith Vijayan, ${ }^{1 \star}$ ShiNung Ching, ${ }^{1,2,3,4 \star}$ Patrick L. Purdon, ${ }^{2,3,4,5}$ Emery N. Brown, ${ }^{2,3,4,6}$ and Nancy J. Kopell ${ }^{1}$ \\ ${ }^{1}$ Department of Mathematics and Statistics, Boston University, Boston, Massachusetts 02215, ${ }^{2}$ Anesthesia, Critical Care, and Pain Medicine, Massachusetts \\ General Hospital, Boston, Massachusetts 02114, ${ }^{3}$ Brain and Cognitive Science, Massachusetts Institute of Technology, Cambridge, Massachusetts 02139, \\ ${ }^{4}$ Harvard Medical School, Boston, Massachusetts 02115, ${ }^{5}$ Athinoula A. Martinos Center for Biomedical Imaging, Charlestown, Massachusetts 02129, and \\ ${ }^{6}$ Institute for Medical Engineering and Science, Massachusetts Institute of Technology, Cambridge, Massachusetts 02139
}

As humans are induced into a state of general anesthesia via propofol, the normal alpha rhythm $(8-13 \mathrm{~Hz})$ in the occipital cortex disappears and a frontal alpha rhythm emerges. This spatial shift in alpha activity is called anteriorization. We present a thalamocortical model that suggests mechanisms underlying anteriorization. Our model captures the neural dynamics of anteriorization when we adjust it to reflect two key actions of propofol: its potentiation of GABA and its reduction of the hyperpolarization-activated current $I_{h}$. The reduction in $I_{h}$ abolishes the occipital alpha by silencing a specialized subset of thalamocortical cells, thought to generate occipital alpha at depolarized membrane potentials $(>-60 \mathrm{mV})$. The increase in GABA inhibition imposes an alpha timescale on both the cortical and thalamic portions of the frontal component that are reinforced by reciprocal thalamocortical feedback. Anteriorization can thus be understood as a differential effect of anesthetic drugs on thalamic nuclei with disparate spatial projections, i.e.: (1) they disrupt the normal, depolarized alpha in posterior-projecting thalamic nuclei while (2) they engage a new, hyperpolarized alpha in frontothalamic nuclei. Our model generalizes to other anesthetics that include GABA as a target, since the molecular targets of many such anesthetics alter the model dynamics in a manner similar to that of propofol.

\section{Introduction}

It has been observed through electroencephalographic (EEG) recordings that, as humans and animals are induced into a state of general anesthesia, there is a spatial shift in power from posterior electrodes to frontal electrodes; this spatial shift in power is called anteriorization (Tinker et al., 1977; Brown et al., 2010; Purdon et al., 2013). Recent studies (Purdon et al., 2013) have clarified the spectral details associated with anteriorization induced by the common GABAergic anesthetic agent propofol $(2,6-$ diisopropylphenols). Induction of general anesthesia with propofol is associated with a marked increase in EEG power in the alpha $(8-13 \mathrm{~Hz})$ band in the frontal cortices (Feshchenko et al., 2004; Cimenser et al., 2011; Supp et al., 2011). Simultaneously, normal "eyes-closed" alpha power in posterior and specifically, in occipital electrodes is severely attenuated (Ci-

Received Dec. 11, 2012; revised April 20, 2013; accepted May 18, 2013.

Author contributions:S.V., S.C.,P.L.P., E.N.B., and N.J.K. designed research;S.V. and S.C. performed research;S.V. and S.C. analyzed data; S.V., S.C., and N.J.K. wrote the paper.

S.V. acknowledges support from National Science Foundation (NSF) Grant DMS-1042134. S.C. acknowledges support from the Burroughs Wellcome Fund. P.L.P. acknowledges support from National Institutes of Health (NIH) New Innovator Award DP2-0D006454 and NIH K-Award K25-NS057580. E.N.B. acknowledges support from NIH Director's Pioneer Award DP1-0D003646 and NIH Director's Transformative Research Award R01 GM104948. N.J.K. acknowledges support from NSF grants DMS-1042134 and DMS-1225647.

*S.V. and S.C. contributed equally to this work.

Correspondence should be addressed to Sujith Vijayan, Department of Mathematics and Statistics, Boston University, Boston, Massachusetts 02215. E-mail: svijayan9@gmail.com.

S. Ching's present address: Department of Electrical and Systems Engineering, Washington University in St. Louis, St. Louis, M0 63130.

DOI:10.1523/JNEUROSCI.5670-12.2013

Copyright $\odot 2013$ the authors $\quad 0270-6474 / 13 / 3311070-06 \$ 15.00 / 0$ menser et al., 2011; Murphy et al., 2011; Purdon et al., 2013). Although many studies have examined and characterized anteriorization over the last 35 years, the mechanisms underlying anteriorization remain poorly understood.

We present a mechanism for anteriorization based on established computational models for frontal and occipital rhythms. Recent modeling work has shown how propofol can modify the dynamics of thalamocortical networks so as to promote frontal alpha oscillations through enhancement of GABAergic inhibition (Ching et al., 2010). A separate model has shown how posterior alpha rhythms can arise through the actions of a subset of thalamocortical (TC) cells, so-called high-threshold thalamocortical neurons, which project to the occipital cortex (Vijayan and Kopell, 2012). The contribution of this paper is to show why propofol and other anesthetics known to act through GABA promote alpha frontally but suppress it posteriorly. We do so by combining and analyzing the two models. We appeal to the multiple molecular targets of propofol: both its effect on GABAergic inhibition and its effect on hyperpolarizationactivated membrane currents (h-currents) (Funahashi et al., 2001; Ying et al., 2006; Lyashchenko et al., 2007). We show that, when these effects are combined, the mechanisms for frontal alpha established in Ching et al. (2010) survive, while those for occipital alpha (Vijayan and Kopell, 2012) do not. Critical to the decrease in alpha in the occipital cortex is the importance of the h-current in creating the alpha timescale and in setting the resting membrane potential in the highthreshold TC cells. In contrast, the thalamic networks that project to frontal regions are not known to possess high- 


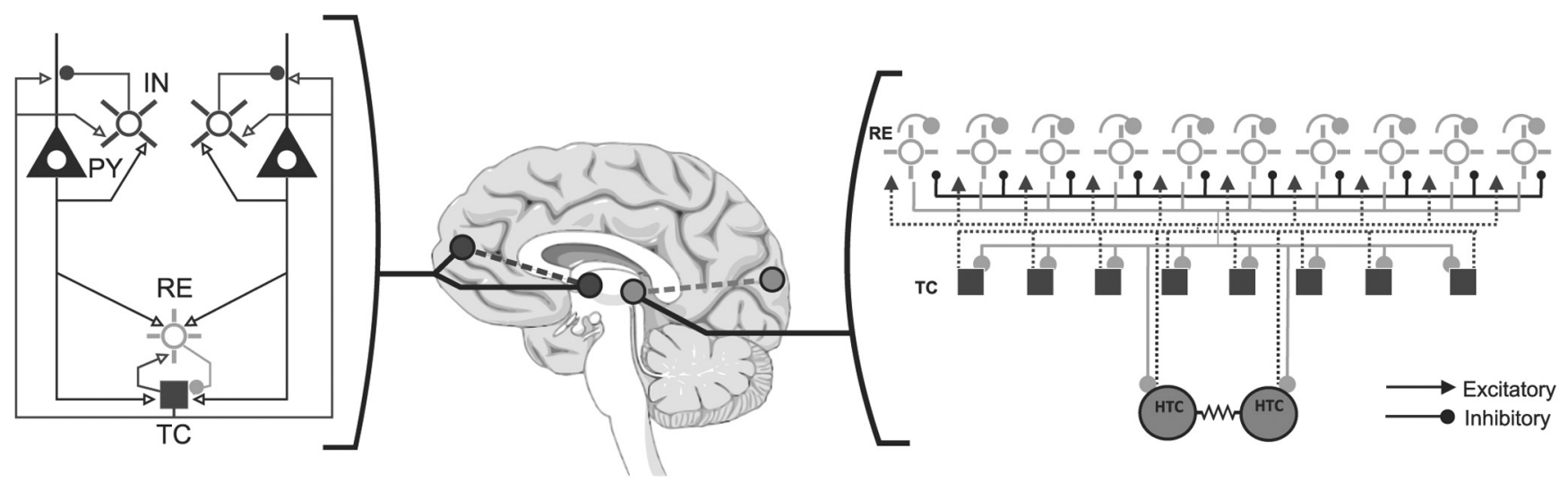

Figure 1. Left, The frontal component consists of cortical PY cells and interneurons coupled to RE and TC. Right, The posterior component consists of TC cells, RE cells, and a specialized subset of TC cells (HTC) that are thought to generate awake alpha.

threshold cells, and the previously studied mechanisms for frontothalamic alpha remain intact, even with reductions to h-current. Given that the molecular targets and requisite effects on neuronal properties that we consider are not exclusive to propofol, our mechanism is expected to be relevant for anteriorization phenomena induced by a range of anesthetic drugs and pathological states.

\section{Materials and Methods Description of computational model}

The model consists of single-compartment Hodgkin-Huxley neurons, where the membrane potential of each cell is governed by the following equation:

$$
\mathrm{C}_{\mathrm{M}} \frac{\mathrm{dV}}{\mathrm{dt}}=-\sum \mathrm{I}_{\mathrm{M}}-\sum \mathrm{I}_{\mathrm{syn}}
$$

where $I_{M}$ denotes membrane currents, $I_{\mathrm{Syn}}$ denotes synaptic currents, and $C_{M}$ denotes the specific membrane capacitance. To capture the dynamics of anteriorization we combine a thalamocortical circuit that can account for the properties of propofol-induced frontal alpha (Ching et al., 2010) with a thalamic circuit that has the properties needed to generate occipital alpha (Vijayan and Kopell, 2012). We briefly describe each in turn below.

Model for frontal thalamocortical network. The structure of the network is shown schematically on the left-hand side of Figure 1, and is essentially unchanged from Ching et al. (2010). A thalamic network model of 10 TC neurons is reciprocally connected to 10 thalamic reticular (RE) neurons. The RE cells provide inhibition to the TC cells, mediated by both $\mathrm{GABA}_{\mathrm{A}}$ and $\mathrm{GABA}_{\mathrm{B}}$, and also provide inhibition to each other, mediated by $\mathrm{GABA}_{\mathrm{A}}$. The TC cells in turn provide excitatory inputs (AMPA) to the RE cells. This configuration is a standard thalamic model structure (Destexhe et al., 1996). For the cortex, eight pyramidal (PY) cells are connected to four inhibitory interneurons (IN). Excitatory connections from TC cells onto PY and IN cells and reciprocal excitatory connections from PY cells onto RE and TC cells form the thalamocortical loop. In addition to standard sodium and potassium channels, notable currents include a T-type calcium current (in the TC and RE cells), a hyperpolarization-activated cation current, $I_{h}$ (in the TC cells), and a potassium leak current, $I_{K L}$ (in the TC cells). In Ching et al. (2010), some interneurons were modeled as low-threshold spiking cells with a slow potassium current $I_{M}$. This current is not essential to the alphagenerating mechanism and is omitted herein. The baseline parameterization of all currents are as specified in Ching et al. (2010).

Model for posterior thalamic network. There is evidence that both the neocortex and the thalamus play a role in generating occipital alpha rhythms (Lopes da Silva et al., 1980; Hughes et al., 2004; Lorincz et al., 2009; Bollimunta et al., 2011; Saalmann et al., 2012). However, we did not include a cortical component in the occipital model. There are two reasons for this. First, the mechanisms underlying the generation of cortical alpha are still poorly understood. Additional experimental work is needed before the construction of a cortical model, and such work is clearly beyond the scope of this paper. Our frontal alpha model relies on a spindling model, for which the cortical component has been well developed (Destexhe et al., 1996). Second, there is experimental evidence suggesting a thalamic model of quiet awake alpha is sufficient for our purposes. Lorincz et al. (2009) have shown in vivo that applying an muscarinic acetylcholine receptor (mAChR) antagonist (pirenzepine) directly to the lateral geniculate nucleus (LGN) can disrupt quiet awake occipital alpha at the EEG level. Specifically, they show that applying an mAChR antagonist directly to the LGN reduces HTC bursting and firing rate, alpha power in the LGN, and alpha power in the EEG over the occipital cortex, all in a dose-dependent manner. Therefore we feel that for our purposes a thalamic model provides a sufficient surrogate for alpha power in the occipital cortex. Note that our occipital model generates alpha by mimicking the effects of $\mathrm{mAchR}$ on the LGN.

The structure of the thalamic network is shown schematically on the right-hand side of Figure 1, and is similar to that used in Vijayan and Kopell (2012). The network consists of 10 RE cells, 8 TC cells, and 2 specialized TC cells (HTC cells). HTC cells are thought to generate awake alpha and make up only $15-25 \%$ of the TC cell population (Hughes et al., 2004; Lorincz et al., 2009). While HTC cells have been reported in the LGN, to the best of our knowledge they have not been reported in frontally projecting thalamic nuclei and so they are not included in the frontal model. The implicit thalamic interneurons used in Vijayan and Kopell (2012) are omitted in our model as their inclusion or exclusion does not affect the results. The connectivity between RE and TC cells (including HTC cells) is the same as for the frontal network, except that HTC cells are connected via gap junctions (Hughes et al., 2011). A critical feature of the HTC cells is that at depolarized membrane potentials $(>-60 \mathrm{mV})$ they burst with the timing between bursts occurring at the alpha frequency. The bursts are mediated by a channel we refer to as $I_{\mathrm{THT}}$, an $I_{T}$ channel variant. The $I_{\mathrm{THT}}$ channel is a type of calcium channel that operates at more depolarized membrane potentials than does the standard $I_{T}$ channel; the use of this channel is based on experimental findings (Hughes et al., 2004; Vijayan and Kopell, 2012). The ionic currents and basal parameterizations are similar to those listed in Vijayan and Kopell (2012) for mAChR agonist-induced alpha.

Propofol simulation. To model the effects of propofol on both the frontal and posterior networks, two perturbations were introduced. First, consistent with previous modeling and experimental studies, the GABA inhibitory synaptic current was potentiated by a factor of three (McCarthy et al., 2008). This perturbation was the primary mechanism studied in Ching et al. (2010) for anterior alpha. Second, the conductance of the hyperpolarization-activated membrane current, $I_{h}$, was decreased to $5.8 \%$ of the baseline value. This latter perturbation, consistent with previous in vitro studies (Chen et al., 2005), was not included in the 


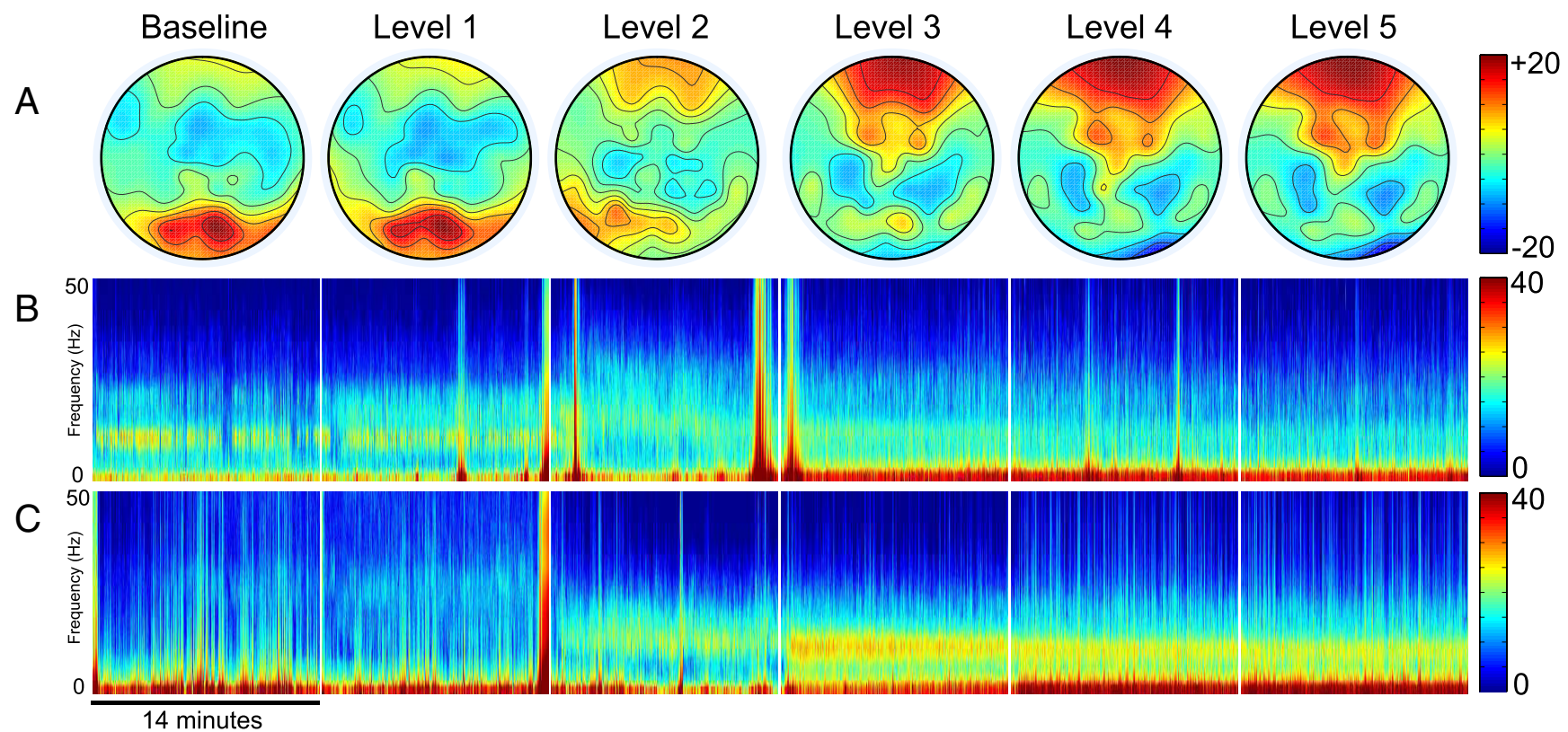

Figure 2. EEG signature of anteriorization during the administration of propofol in a representative human subject. $A$, Power maps of $10.3 \mathrm{~Hz}$ activity. Baseline indicates the subject is at rest and Levels 1-5 indicate increasing effect site concentration levels of propofol. $\boldsymbol{B}$, Spectograms from a posterior electrode. C, Spectograms from a frontal electrode.

model of Ching et al. (2010), but, as shown herein, does not appreciably affect the overall mechanism.

The simulated EEG was computed as the sum of excitatory postsynaptic currents in PY neurons of the frontal model, although the findings regarding alpha genesis also hold when the simulated EEG is computed using the other cell populations, or using membrane potential. The simulated EEG for the posterior model was computed as a function of the membrane potential of HTC cells, since experimental results suggest that blocking synaptic currents does not abolish awake thalamic alpha (Hughes et al., 2004).

Model robustness. Since the circuits underlying our model are known to be able to generate spindles, we ensured our model could generate spindles; this helped to constrain our parameter values. The occipital alpha frequency is sensitive to changes in $I_{h}$ and potassium leak conductances and the frequency changes in a relatively smooth fashion as a function of these conductances; these dependencies are detailed in Vijayan and Kopell (2012). Our results under the propofol conditions are robust to either a $50 \%$ decrease or a $50 \%$ increase of $I_{h}$, potassium leak, and $\mathrm{GABA}_{\mathrm{A}}$ conductances.

\section{Human data and analysis}

All electrophysiologic data were collected at Massachusetts General Hospital (MGH) with approval from the Partners Human Research Committee (Cimenser et al., 2011 and Purdon et al., 2013). We recorded 64 leads of EEG while the subject received propofol administered by a computer-controlled infusion. The infusion was designed to achieve effect site concentration levels of $0,1,2,3,4$, and $5 \mu \mathrm{g} / \mathrm{ml}$. Each level was maintained for $14 \mathrm{~min}$. The infusion was controlled by the STANPUMP algorithm using the Schnider pharmacokinetics model (Shafer and Gregg, 1992; Schnider et al., 1999). All analyses were performed using a Laplacian montage. Power spectrums were calculated with the Chronux toolbox (Bokil et al., 2010) for MATLAB (MathWorks), using $2 \mathrm{~s}$ nonoverlapping windows. Power maps that display the intensity of $10.3 \mathrm{~Hz}$ EEG activity over the surface of the scalp were calculated using the spectopo function in the EEGLAB toolbox (Delorme and Makeig, 2004). Each power map used all data from one of the 14 min conditions.

\section{Results}

\section{Phenomenology}

During rest with eyes closed, alpha activity is predominantly observed in the occipital cortices (Fig. 2A, Baseline and Level 1;
Berger, 1929). However, as subjects are administered increasing doses of propofol the power in the alpha band attenuates in occipital regions and increases in frontal regions (Fig. $2 A$, Level 3-5). The attenuation in alpha power occipitally can be observed in single posterior electrodes (Fig. $2 B$ ) and its increase frontally can be observed in single frontal electrodes (Fig. $2 C$ ). The transition from posterior to anterior alpha regimes occurs quite abruptly during Level 2 of anesthetic induction (Ching et al., 2010). Our focus is to elucidate the essential mechanisms of this state change.

\section{Network behavior during baseline conditions}

During the resting state alpha activity is prominent in the occipital cortices. In vivo and in vitro studies suggest that introducing mAChR agonists into the LGN induces occipital alpha activity closely resembling that seen during the resting state (Lorincz et al., 2009). Therefore we adjusted the parameter values (Vijayan and Kopell, 2012) of the occipital component to reflect the actions of mAChR agonists. Under these conditions the TC cells spike irregularly in the occipital component (Fig. $3 F$ ), but the RE cells are relatively silent (Fig. $3 G$ ); note that the relative inactivity of RE cells during awake alpha is in line with experimental findings (Lorincz et al., 2009). The HTC cells, thought to be the generators of awake alpha, fire at the alpha frequency, resulting in a peak at the alpha frequency in the power spectrum of the local field potential (LFP; Fig. 3E,H). Under these conditions, the HTC cells are relatively depolarized $(\sim-52 \mathrm{mV})$. At these membrane potentials $I_{\mathrm{THT}}$ channels, which are variants of $I_{T}$ channels (see Materials and Methods), are active and help to mediate the bursting activity. $I_{h}$ imposes the alpha timescale on the bursting. During this resting state PY cells, TC cells and RE cells in the frontal component spike irregularly (Fig. $3 A-C$ ). The power spectrum of the resulting LFP is relatively flat (Fig. $3 D$ ).

\section{Network behavior in the presence of propofol}

To account for the actions of propofol we reduced the $I_{h}$ conductance and increased the $\mathrm{GABA}_{\mathrm{A}}$ conductance (see Materials and 

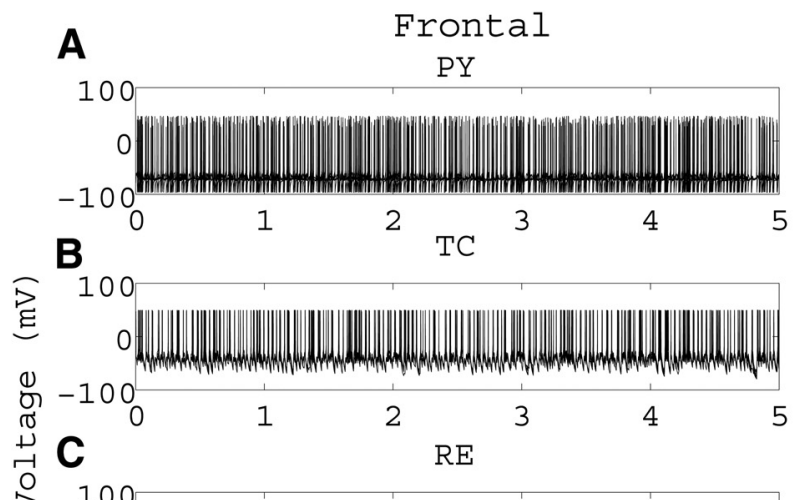

$\stackrel{0}{p} 100$

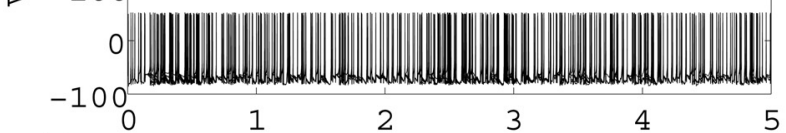

D

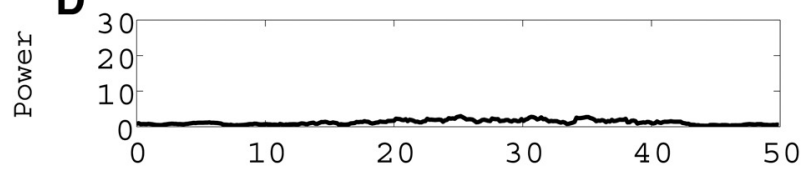

E

Occipital

HTC

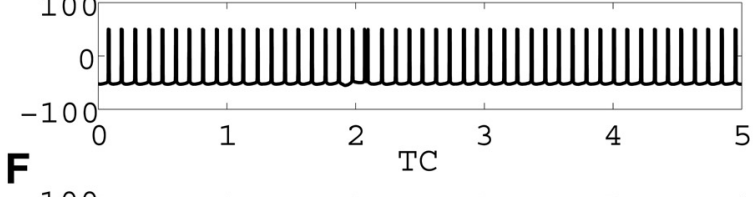

F

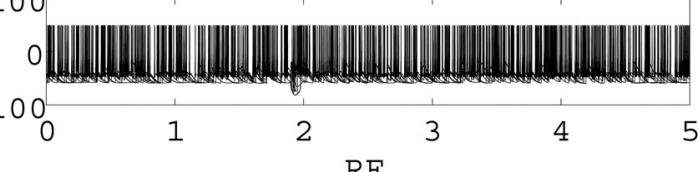

G

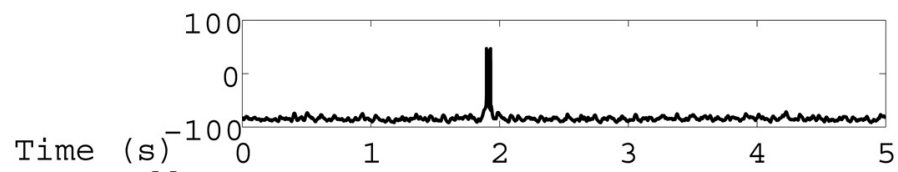

H

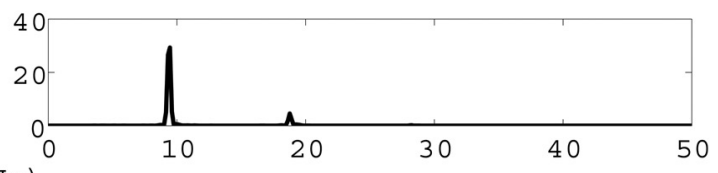

Figure 3. Activity pattern and power spectrum of the LFP of the frontal and occipital circuits during the resting state. $A$, Spiking activity of PY neurons, (B) TC neurons, (C) RE neurons, (D) and LFP of frontal component. $\boldsymbol{E}$, Spiking activity of HTC neurons, $(\boldsymbol{F})$ TC neurons, $(\boldsymbol{G})$ RE neurons, $(\boldsymbol{H})$ and LFP of occipital component.
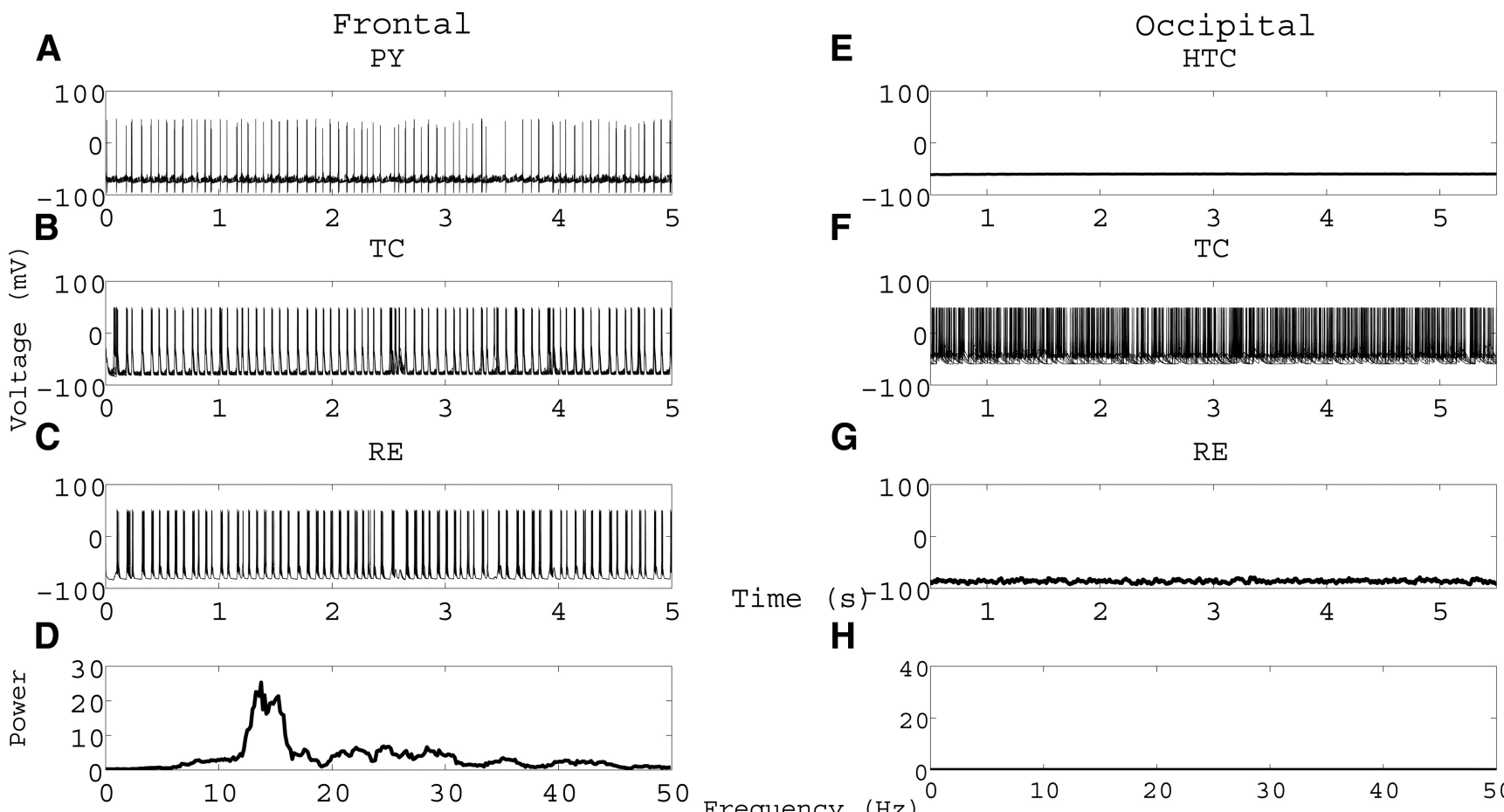

H

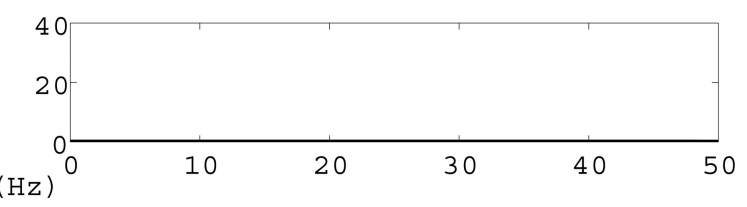

Figure 4. Activity pattern and power spectrum of the LFP of the frontal and occipital circuits during propofol-induced anesthesia. $\boldsymbol{A}-\boldsymbol{H}$, Same as in Fig. 3.

Methods) in both components. The primary effect on the occipital circuit is the silencing of HTC cells (Fig. 4E-G). The HTC cells become silent for two reasons: First, $I_{h}$ helps the HTC cells transition from the interburst period to the beginning of the next burst. That is, after one burst finishes, $I_{h}$ helps to depolarize the cell, priming it for the following burst; since $I_{h}$ conductance is reduced by propofol it is no longer strong enough to move the cell toward the next burst. Second, the reduction in $I_{h}$ conductance shifts the resting membrane potential of HTC cells to more hy- perpolarized values $(\sim-60 \mathrm{mV})$, since $I_{h}$ has a relatively positive reversal potential. At these more hyperpolarized membrane potentials, $I_{\mathrm{THT}}$ channels, which mediate the burst itself, are relatively quiet. Note that HTC cells can be silenced without altering $I_{h}$ by shifting the cell membrane potential outside the active range of $I_{\mathrm{THT}}$ channels. For example, the single change of increasing potassium leak conductances results in the silencing of HTC cells, as this increase shifts the membrane potential of HTC cells to more hyperpolarized values (Vijayan and Kopell, 2012). The si- 
lencing of HTC cells, which are the putative generators of awake alpha, results in the LFP power spectrum of the posterior component being relatively flat (Fig. $4 H$ ).

In the frontal component an alpha rhythm emerges (Fig. 4A$D)$. Propofol acts on the frontal circuit to produce alpha in two ways. First, the potentiation of $\mathrm{GABA}_{\mathrm{A}}$ increases the time constant of inhibition mediated by cortical interneurons impinging onto PY neurons. This increase in inhibition causes an overall slowing of high-frequency cortical activity to bring it into the alpha range (Fig. 4A). Simultaneously, the increase in $\mathrm{GABA}_{\mathrm{A}}$ conductance hyperpolarizes the thalamic portion of the network, mediated by inhibitory RE cells (Fig. $4 B, C$ ). This results in a strengthening of endogenous thalamic alpha mechanisms, mediated by hyperpolarization-activated currents in TC cells, creating what amounts to a persistent oscillation between RE and TC cells at the alpha frequency. Consequently, the thalamic and cortical networks synchronize within the alpha band, promoting coherence in frontothalamic networks. In particular, ascending TC neurons fire at the alpha frequency (Fig. 4B), exciting cortical INs that pace PY cells (Fig. 4A). The reciprocal excitation from these PY cells onto both RE and TC neurons forms a closed loop and reinforces the oscillation. This overall mechanism is similar to that presented by Ching et al. (2010) with the notable exception that, there, propofol-induced modifications to $I_{h}$ were not considered. Here, we find that these reductions do not appreciably modify the mechanism, and the genesis of alpha in the frontothalamic model is preserved.

As mentioned above, we have focused here on the mechanism of the state change between the posterior and anterior alpha regimes. We note from both the data and analyses performed in Ching et al. (2010) that the frontal alpha coherence develops rather abruptly as a function of propofol infusion. At progressively increasing dose levels, the specific frequency of the alpha oscillation may attenuate slightly, although eventually secondary effects such as decreases in blood flow and metabolism will lead to other phenomena such as burst suppression (Ching et al., 2012).

We note important distinctions between the alpha mechanisms we develop here and those of spindle oscillations. During spindling TC cells do not fire at the spindling frequency: groups of TC cells participate in the spindling oscillation missing many cycles (Destexhe et al., 1996). In contrast, in our model of frontal alpha, individual TC cells oscillate at the alpha frequency. Furthermore, the amplitude envelope of spindles waxes and wanes, and spindles occur infrequently (Destexhe et al., 1996). In contrast, the frontal alpha is sustained, because GABA potentiation imposes a similar timescale on PY cells as on TC cells. Thus, the reciprocal corticothalamic feedback forms a closed loop that reinforces the oscillation, leading to persistent activity.

\section{Discussion}

\section{A thalamocortical model for anteriorization}

Our model offers an explanation of the mechanism for propofolinduced anteriorization. It suggests that alpha activity in the occipital component is abolished because the reduction of $I_{h}$ conductance silences HTC cells, the putative generators of occipital alpha. HTC cells stop bursting at the alpha frequency because at the reduced $I_{h}$ conductance, $I_{h}$ is no longer able to help transition the cell from the interburst period to bursting. Furthermore, the reduction in the $I_{h}$ conductance hyperpolarizes HTC cells to a membrane potential outside the operating range of $I_{\mathrm{THT}}$, which underlie the bursts themselves. Our model also suggests that alpha activity in the frontal component arises from increased
GABAergic inhibition onto TC cells, which creates alpha timescales that are reinforced by reciprocal corticothalamic feedback.

\section{Model relevance to other anesthetics and pathological states}

The extent to which anteriorization occurs in response to anesthetics other than propofol is an open question, since EEG studies of drugs other than propofol (Gugino et al., 2001; John et al., 2001) have averaged effects over different drug classes.

In our model, the critical mechanism in abolishing occipital alpha is the silencing of HTC cells, and the critical mechanism in producing frontal alpha is the potentiation of GABA. We thus predict that anteriorization may arise in response to drugs that share these molecular targets and the requisite effects on neuronal populations. For example, isoflurane, sevoflurane, and halothane potentiate GABA (Franks and Lieb, 1994; Rudolph and Antkowiak, 2004). Also, all three silence HTC cells, as they all increase potassium leak conductances (Shin and Winegar, 2003; Enyedi and Czirják, 2010); increasing potassium leak conductances silences HTC cells by hyperpolarizing them and moving them out of the operating range of $I_{\mathrm{THT}}$ channels, which are responsible for mediating the awake alpha bursts.

Our model is in accordance with the observation that anesthetics that potentiate GABA but also alter currents other than $I_{h}$ or potassium leak conductance can produce a spectral pattern different from that of propofol. For example, like propofol, barbiturates are known to potentiate GABA and reduce $I_{h}$ conductance (Wan et al., 2003), but they also have other molecular targets (Solt and Forman, 2007; Franks and Zecharia, 2011). In particular, it is known they attenuate AMPA (Taverna et al., 1994; Löscher and Rogawski, 2012). Such a perturbation is expected to prevent the expression of the thalamocortical alpha mechanism developed here. Specifically, the frontal alpha oscillation relies on the "ping-pong" relationship between RE and TC cells: TC cells excite RE cells via AMPA, causing the RE cells to spike; their spiking inhibits TC cells via GABA, causing TC cells to spike again, as currents that are more active at hyperpolarized membrane potentials $\left(I_{T}\right.$ and $\left.I_{h}\right)$ become engaged. Thus attenuating AMPA conductances disrupts the critical interplay between RE and TC cells. TC cells also drive PY cells, via AMPA, at the alpha frequency. Therefore AMPA reduction will disrupt multiple facets of the alpha-generating mechanism in our model. In fact, model simulations show that reducing AMPA conductance by $25-30 \%$ begins to disrupt frontal alpha, and reducing it by $50 \%$ abolishes frontal alpha altogether.

We note, also, that certain pathological states of unconsciousness, such as alpha coma (Kaplan et al., 1999), are characterized by anteriorly dominant alpha EEG patterns. While much work remains in characterizing these conditions, our model may eventually help to inform thalamocortical mechanisms in these pathological states.

\section{References}

Berger H (1929) On the electroencephalogram of man. Arch Psychiatr Nervenkr 87:527-570. CrossRef

Bokil H, Andrews P, Kulkarni JE, Mehta S, Mitra PP (2010) Chronux: a platform for analyzing neural signals. J Neurosci Methods 192:146-151. CrossRef Medline

Bollimunta A, Mo J, Schroeder CE, Ding M (2011) Neuronal mechanisms and attentional modulation of corticothalamic alpha oscillations. J Neurosci 31:4935-4943. CrossRef Medline

Brown EN, Lydic R, Schiff ND (2010) General anesthesia, sleep, and coma. N Engl J Med 363:2638-2650. CrossRef Medline

Chen X, Shu S, Bayliss DA (2005) Suppression of ih contributes to propofolinduced inhibition of mouse cortical pyramidal neurons. J Neurophysiol 94:3872-3883. CrossRef Medline 
Ching S, Cimenser A, Purdon PL, Brown EN, Kopell NJ (2010) Thalamocortical model for propofol-induced alpha rhythm associated with loss of consciousness. Proc Natl Acad Sci U S A 107:22665-22670. CrossRef Medline

Ching S, Purdon PL, Vijayan S, Kopell NJ, Brown EN (2012) A neurophysiological-metabolic model for burst suppression. Proc Natl Acad Sci U S A 109:3095-3100. CrossRef Medline

Cimenser A, Purdon PL, Pierce ET, Walsh JL, Salazar-Gomez AF, Harrell PG, Tavares-Stoeckel C, Habeeb K, Brown EN (2011) Tracking brain states under general anesthesia by using global coherence analysis. Proc Natl Acad Sci U S A 108:8832-8837. CrossRef Medline

Delorme A, Makeig S (2004) EEGLAB: an open source toolbox for analysis of single trial EEG dynamics including independent component analysis. J Neurosci Methods 134:9-21. CrossRef Medline

Destexhe A, Bal T, McCormick DA, Sejnowski TJ (1996) Ionic mechanisms underlying synchronized oscillations and propagating waves in a model of ferret thalamic slices. J Neurophysiol 76:2049-2070. Medline

Enyedi P, Czirják G (2010) Molecular background of leak K+ currents: two-pore domain potassium channels. Physiol Rev 90:559-605. CrossRef Medline

Feshchenko VA, Veselis RA, Reinsel RA (2004) Propofol-induced alpha rhythm. Neuropsychobiology 50:257-266. CrossRef Medline

Franks NP, Lieb WR (1994) Molecular and cellular mechanisms of general anaesthesia. Nature 367:607-614. CrossRef Medline

Franks NP, Zecharia AY (2011) Sleep and general anesthesia. Can J Anaesth 58:139-148. CrossRef Medline

Funahashi M, Higuchi H, Miyawaki T, Shimada M, Matsuo R (2001) Propofol suppresses a hyperpolarization-activated inward current in rat hippocampal CA1 neurons. Neurosci Lett 311:177-180. CrossRef Medline

Gugino LD, Chabot RJ, Prichep LS, John ER, Formanek V, Aglio LS (2001) Quantitative EEG changes associated with loss and return of consciousness in healthy adult volunteers anaesthetized with propofol or sevoflurane. Br J Anaesth 87:421-428. CrossRef Medline

Hughes SW, Lörincz M, Cope DW, Blethyn KL, Kékesi KA, Parri HR, Juhász G, Crunelli V (2004) Synchronized oscillations at alpha and theta frequencies in the lateral geniculate nucleus. Neuron 42:253-268. CrossRef Medline

Hughes SW, Lőrincz ML, Blethyn K, Kékesi KA, Juhász G, Turmaine M, Parnavelas JG, Crunelli V (2011) Thalamic gap junctions control local neuronal synchrony and in-fluence macroscopic oscillation amplitude during EEG alpha rhythms. Front Psychol 2:193. CrossRef Medline

John ER, Prichep LS, Kox W, Valdés-Sosa P, Bosch-Bayard J, Aubert E, Tom M, di Michele F, Gugino LD (2001) Invariant reversible QEEG effects of anesthetics. Conscious Cogn 10:165-183. CrossRef Medline

Kaplan PW, Genoud D, Ho TW, Jallon P (1999) Etiology, neurologic correlations, and prognosis in alpha coma. Clin Neurophysiol 110:205-213. CrossRef Medline

Lopes da Silva FH, Vos JE, Mooibroek J, Van Rotterdam A (1980) Relative contributions of intracortical and thalamo-cortical processes in the generation of alpha rhythms, revealed by partial coherence analysis. Electroencephalogr Clin Neurophysiol 50:449-456. CrossRef Medline

Lorincz ML, Kékesi KA, Juhász G, Crunelli V, Hughes SW (2009) Temporal framing of thalamic relay-mode firing by phasic inhibition during the alpha rhythm. Neuron 63:683-696. CrossRef Medline
Lyashchenko AK, Redd KJ, Yang J, Tibbs GR (2007) Propofol inhibits HCN1 pacemaker channels by selective association with the closed states of the membrane embedded channel core. J Physiol 583:37-56. CrossRef Medline

McCarthy MM, Brown EN, Kopell N (2008) Potential network mechanisms mediating electroencephalographic beta rhythm changes during propofol-induced paradoxical excitation. J Neurosci 28:13488-13504. CrossRef Medline

Murphy M, Bruno MA, Riedner BA, Boveroux P, Noirhomme Q, Landsness EC, Brichant JF, Phillips C, Massimini M, Laureys S, Tononi G, Boly M (2011) Propofol anesthesia and sleep: a high-density EEG study. Sleep 34:283-291A. Medline

Purdon PL, Mukamel EA, Prerau MJ, Walsh JL, Wong KFK, Salazar-Gomez AF, Harrell PG, Sampson A, Cimenser A, Ching S, Kopell N, TavaresStoeckel CL, Habeeb K, Merhar R, Brown EN (2013) Electroencephalogram signatures of loss and recovery of consciousness from propofol. Proc Natl Acad Sci U S A

Rudolph U, Antkowiak B (2004) Molecular and neuronal substrates for general anaesthetics. Nat Rev Neurosci 5:709-720. CrossRef Medline

Saalmann YB, Pinsk MA, Wang L, Li X, Kastner S (2012) The pulvinar regulates information transmission between cortical areas based on attention demands. Science 337:753-756. CrossRef Medline

Schnider TW, Minto CF, Shafer SL, Gambus PL, Andresen C, Goodale DB, Youngs EJ (1999) The influence of age on propofol pharmacodynamics. Anesthesiology 90:1502-1516. Medline

Shafer SL, Gregg KM (1992) Algorithms to rapidly achieve and maintain stable drug concentrations at the site of drug effect with a computercontrolled infusion pump. J Pharmacokinet Biopharm 20:147-169. Medline

Shin WJ, Winegar BD (2003) Modulation of noninactivating K+ channels in rat cerebellar granule neurons by halothane, isoflurane, and sevoflurane. Anesth Analg 96:1340-1344, table of contents. Medline

Solt K, Forman SA (2007) Correlating the clinical actions and molecular mechanisms of general anesthetics, Curr Opin Anaesthesiol 20:300306.

Supp GG, Siegel M, Hipp JF, Engel AK (2011) Cortical hypersynchrony predicts breakdown of sensory processing during loss of consciousness. Curr Biol 21:1988-1993. CrossRef Medline

Taverna FA, Cameron BR, Hampson DL, Wang LY, MacDonald JF (1994) Sensitivity of AMPA receptors to pentobarbital. Eur J Pharmacol 267:R3R5. CrossRef Medline

Tinker JH, Sharbrough FW, Michenfelder JD (1977) Anterior shift of the dominant EEG rhythm during anesthesia in the JAVA monkey. Anesthesiology 46:252-259. CrossRef Medline

Vijayan S, Kopell NJ (2012) Thalamic model of awake alpha oscillations and implications for stimulus processing. Proc Natl Acad Sci U S A 109:18553-18558. CrossRef Medline

Wan X, Mathers DA, Puil E (2003) Pentobarbital modulates intrinsic and GABA-receptor conductances in thalamocortical inhibition. Neuroscience 121:947-958. CrossRef Medline

Ying SW, Abbas SY, Harrison NL, Goldstein PA (2006) Propofol block of I(h) contributes to the suppression of neuronal excitability and rhythmic burst firing in thalamocortical neurons. Eur J Neurosci 23:465-480. CrossRef Medline 